\title{
Vocational Counselling and Transition Skill Training for Adolescents with Special Needs
}

\author{
Atasi Mohanty \\ Centre for Educational Technology, IIT Kharagpur, Kharagpur, West Bengal, India \\ Email: atasim@cet.iitkgp.ernet.in
}

Received 5 February 2015; accepted 23 February 2015; published 27 February 2015

Copyright (C) 2015 by author and Scientific Research Publishing Inc.

This work is licensed under the Creative Commons Attribution International License (CC BY). http://creativecommons.org/licenses/by/4.0/

(c) (i) Open Access

\begin{abstract}
Adolescence is a period of transition from childhood to adulthood which implies many developmental changes and challenges. One of the most critical turning points in the lives of adolescents is the transition from schools to the world of post-secondary education, employment, and life in the general community as an adult. Developing independence, examining one's talents and interests, deciding upon a career path and pursuing either employment or additional schooling are just some of the challenges that youth in transition face. Moreover, the children with specific disability and special needs are faced with some serious challenges like un-employability, social maladjustment, and emotional disturbance etc. as the period of transition approaches. These adolescents are unemployed at a higher rate than their general peers, tend to drop out of school halfway, and are more likely to get involved with criminal activities. Thus, the education and rehabilitation of these young children with special needs has really become a challenging field in recent time. Counseling and informal education generally would enable these exceptional children to overcome their disability to a large extent and make them effective individuals in the society. The present paper highlights some of these crucial issues.
\end{abstract}

\section{Keywords}

Vocational Counselling, Transition Skill Training, Adolescents with Special Needs, Rehabilitation

\section{Introduction}

Any period of change is likely to be accompanied by many potential difficulties. Adolescence is a period of transition from childhood to adulthood, which implies many developmental changes and challenges. Thus, the children with specific disability/special needs would certainly grow up to be adolescents and young adults with disabilities and special needs. One of the most critical turning points in the lives of young people is the transition 
from schools to the world of post-secondary education, employment, and life in the general community as an adult. Developing independence, examining one's talents and interests, deciding upon a career path, and pursuing either employment or additional schooling are just some of the challenges that youth in transition face. Moreover, the studies show, the students with special needs are faced with serious challenges like un-employability, social maladjustment, emotional disturbances etc. as the period of transition approaches (Kransntover, Thurlow, \& Bruininks, 1989; National Transition Longitudinal Study, 1994, USA). These adolescents are unemployed at a higher rate than their non-disabled peers; they tend to drop out of school half the way; they are more likely to get involved with the criminal system to a great extent and tend to be living in a dependent situation for a longer period of time (Edgar, 1988). Thus, the education and rehabilitation of exceptional children is really a challenging field. In India, according to a report of the National Sample Survey Organization - 2002, the number of handicapped persons (in India) is 1.85 Crore and they formed $1.8 \%$ of the total estimated population. About $10.63 \%$ of the handicapped persons are suffering from more than one type of disability. Approximately, India has 30 million children with different disabilities. At present only $1 \%$ to $2 \%$ of them are in schools. In contrast to this picture, Article 45 of the Indian Constitution directs that free and compulsory education should be provided to all children, which implicitly cover those who are handicapped/disabled. Counselling and education generally enable an exceptional child to overcome largely his exceptionality and make him an effective and useful individual. Social justice also demands it. Thus, the primary objective of this paper is to provide and suggest some information and strategies for helping adolescents and young children with special needs to make a successful transition from school to the adult-community.

Every year thousands of students with special needs exit high school and face the demands of independent living settings, post-secondary education programmes and, ultimately unemployment. World Health Organization (WHO) in one of its report stressed the fact that individual development and social contribution of adolescents will shape the future of the world and therefore, investment in children's health, nutrition and education is the foundation for national development. In view of this, providing for education and training of an enormous number of adolescents with special needs is an immense undertaking. The primary task in this context is to prepare these children not only to become independent and earn their livelihood but also for adjustment to their socio-cultural environment.

The transition literature suggests that students with special needs require self-advocacy training, employability skills training, systematic referral to adult agencies, life skills education, family involvement, and immediate and ongoing job support in order to obtain and maintain employment over time (Clark, 1994; Wehman, 1993; WHO, 1997). Hence, comprehensive transition skills, employability skills and related social skills must be taught during the high school years to assure student success in the adult world. During the elementary and middle school years, special education services tend to emphasize academic skills. As students with disabilities enter adolescence and young adulthood, a greater emphasis is placed on vocational and general life skills. This is commonly referred to as career education.

Career education includes more than just vocational training/counselling and job placement. This refers to the total process of preparing exceptional individuals for the many roles of adulthood. Career education prepares individuals with disabilities for the several life roles which make up an individual's career. These life roles may include an economic role, a community role, a home role, and an aesthetic role. The transition skill training/services refer to even more comprehensive and coordinated set of activities than just career education or vocational counselling. Transition services are designed within an outcome-oriented process, which promote movement from school to post-school activities, including post-secondary education, vocational training, integrated employment, continuing and adult education, adult services, independent living, life skills training, community participation etc. These set of activities should be based upon the individual student's needs, taking into account his/her preferences, interests and would include instruction, counselling, community experience, the development of employment and other post school/adult living objectives and acquisition of daily living skills and functional vocational evaluation. In recent times several world organizations i.e., WHO (1997), UNESCO (2001) have also stressed on life skills training for adolescents for the acquisition of abilities for adaptive and positive behavior that enable the teenagers to deal effectively with the demands and challenges of everyday life.

\section{E Components of Transitional Skill Training: Vocational Skills}

\subsection{Job Search Skills}

FA critical element in any transition program for high school students with special needs is a job-search curri- 
culum. Adolescents with disabilities need instruction in skills like conducting a personal job search, filling out job applications correctly and preparing a resume (Patton, 1991), as well as alternatives such as school-based vocational development and placement. The vocational counsellors whenever organizing some transition programmes should infuse some of these guidelines i.e.,

1) Include at least 2 to 3 weeks of skill building in how to search for job opportunities;

2) Include instruction in developing a resume;

3) Include instruction in filling out job applications neatly, accurately and completely;

4) Include instruction in how to give interview for a job, the critical communication skills required for a success full job interview;

5) Include instruction on what essential documents are needed for getting a job etc.

\subsection{Job Maintenance Skills}

Job success depends more on effective job maintenance skills such as communication and interpersonal skills and good work habits than upon actual job skills. Employers consider worker behaviors and attitudes to be important for job performance. In a study when employers were asked to rank factors judged to be critical to job success for workers with disabilities, the five highest ranking factors were: 1) getting along well with others; 2) interest in the job; 3) efficiency; 4) dependability; and 5) being able to adapt to new work situations (Chamberlain, 1988). Students with special needs can be jeopardized by their "hidden" disability, which manifests itself in the work-place as inappropriate socialization, lack of initiative, poor attitude, defiance, and other behaviors which cause loss of jobs early on. Hence, adolescents with disabilities require systematic instruction in order to learn and practice the critical skills of keeping a job. They also need on-the-job support to ensure that appropriate job maintenance skills have been generalized in the workplace over time. The high school curriculum and transition programme must incorporate some of these guidelines/principles such as:

1) Include at least a semester-long course in job maintenance skills emphasizing a job-keeping behaviors and job related social behaviors;

2) Include opportunities for part-time jobs while enrolled in a job maintenance skills course;

3) Providing ongoing and frequent support to working students, the strategies may include teaching skills on the job, employer communication etc.

\subsection{Job-Related Functional Academics}

Reading and writing on the job, figuring computations, estimating, making change, and using time wisely are functional academic skills that can be taught in the classroom to help students succeed on the job. Students with special needs are unable to generalize transitional academics to the real world of employment and adult living. Job related functional academics such as counting change, operating cash registers, and calculating net and gross pay are easily infused in to the regular math course.

\subsection{Mobility and Transportation Skills}

The need for mobility skills has long been recognized by educators of individuals with severe disabilities (Laus, 1977), but overlooked by educators of students with mild disabilities. Students cannot be successful on the job if they cannot get to and from their jobs. A majority of students with mild disabilities depend on public transit for transportation. As the urban transit systems are extremely complex students with special needs have difficulty in understanding the bus routes, transfer points and directions etc. In addition they are generally naive about safety practices and appropriate social interactions when using public transit. Hence, the school curriculum at secondary level should include opportunities for students to learn, practice and generalize the skills of:

1) applying for bus passes; 2) reading and interpreting bus route information; 3) using public transit safety including road safety and emergency strategies; 4) using actual routes from home and school to places of work; and 5) travelling independently from home to school to a work site.

\section{Counselling for Post-Secondary/Vocational Education}

Transition programmes should include structured planning for recreation activities and community collaboration which can guide the youths towards healthy recreational pursuits. School counsellors should take a more active 
role in career planning for students with disabilities and initiate early career planning with parents and students. Students need to become aware of the many programs that can help them beyond high school, including community college programs, disabled student services, occupational preparation programs, vocational training programs, and adult agency services. It is found from the study that students before high school completion are more likely to stay in school, remain employed after school completion, seek post-secondary education opportunities, and become self-supporting adults (Edgar, 1987). Hence, school counsellors should become an integral part of the transition team, so they are informed and knowledgeable about the multitude of post-school program options for these students. High school special education teachers, job coaches and other special education support personnel can play a vital role in the transition programme for successful living.

\section{Training of Self-Advocacy Skills}

Self-advocacy, or speaking for oneself, is a big part of living in the community. The ability to advocate for oneself on the job and in the community is essential. Young adults with disabilities who live in the community should have the right to make their own decisions, just like anyone else. Hence, during high school, students need to learn how to advocate for themselves and how to be proactive participants in their transition planning process. Transition planning models also stress that parent involvement should be an integral part of transition planning for youth with special needs. Michaels (1989) claims that specific job maintenance skills must be taught to lead to self advocacy. He recommends curriculum including the information on:

- Accepting criticism, changing behavior to reflect input;

- Dealing with supervisors/managers, including discussing the disability and requesting appropriate accommodations;

- Self evaluation of performance, monitoring task completion, and providing self-feedback;

- Goal-setting, including developing short and long-term goals, and monitoring progress;

- Developing a vocational plan that includes goals for career advancement, job upgrading, and how to protect one's interest; and

- Developing social skills and appropriate behavior/interactions for the job setting.

Schools should also set target goals for parent participation in transition planning and frequently monitor the extent and quality of parent participation (Cobb \& Brody-Hasazi, 1987). Parent involvement should also be an integral part of transition planning for youth with special needs. Family members need to be taught the effective strategies for supporting the efforts of a working student, strategies for accessing adult community services, and other information specific to their youth's transition from school to the adult community. The parental training activities should include certain activities i.e., providing incentives for parents' participation, someone should be given the responsibility as family coordinator specialist (in the transition team) who should make as many home visits as possible. For the purpose of informing family members about the transition programs as well as about the adult living and employment goals for the students the coordinators are supposed to handle the family involvement in a very sensitive and appreciative manner. Adolescents/adults with developmental disabilities can and should have an impact on services by participating in agency boards and training activities. They have the right to learn to speak for themselves. It's important because there will be a day when our parents won't be able to speak for us. Hence, disabled children can be trained to teach each other how to speak for themselves. Roleplaying a variety of problems or situations is a good way to learn self-advocacy. There is more strength in forming a group. People speaking through a common platform can have a better chance/scope of catching attention and listening to their problems. Clark and Kolstoe (1990) emphasize the importance of the "Individualized Transition Plan” (ITP) in increasing a student's chances for success after high school. The transition team must include the student, family members, school personnel, adult agency personnel, community liaisons, and other supporting staff. Planning for instruction and services must include the period, and the first few months of independent adult living. It should include all aspects of transition instruction and services including job search skills, job maintenance skills, transportation training, recreation activities, placement and support, paid part-time jobs during high school, early referral to adult agencies, self-advocacy skills, parent involvement, plans for high school exit, and any other instruction and services specific to the individual students' needs. Planning should include a follow-up evaluation of the delivery of transition services for all adolescents with special needs.

\section{Training of Social and Life Skills}

WHO has defined life skills "as the abilities for adaptive and positive behavior that enable individuals to deal 
effectively with the demands and challenges of everyday life” (WHO, 1997). Skills thus, enable us to translate knowledge, attitudes and values into actual abilities to know what to do? When to do? How to do? When faced with real life situations? Skills also enable us to behave in healthy way and think and act with logic and sensitivity skills needed are also determined by temporal and spatial considerations. The same skills may not be relevant or useful in all the occasions all the time. The same may be applicable to individuals across culture and regions (INC and UNESCO 2001). There is a core set of skills needed that are needed for the promotion of health and well being of children and adolescents, such as thinking skills, daily living skills, social skills, negotiation skills, non-judge mental skills, empathy skills etc. Self-awareness is the first life skill. The adolescents with special need can be made aware of their rights, duties and responsibilities towards themselves as well as society. They can also be trained to develop skills to think critically by providing them different opportunities to look at different perspectives of an issue the pros and cons of allowing one decision over the other and making them realize the negative consequences of making hasty and unplanned decisions. The daily living skills include managing personal finances, selecting and managing a household, caring for personal needs, raising children and meeting marriage responsibilities, buying, preparing and consuming food, clothing, using recreational facilities and engaging in leisure, getting around the community and exhibiting responsible citizenship etc. The social skills include appreciating others, working with others, understanding their roles, building positive relationships with friends, family and peers including the opposite sex, listening and communicating effectively, taking responsibility and coping with stress. Social skills enable the adolescents to be accepted in society and to accept social norms that provide foundation for adult social behavior. Many adolescents with special needs have very little idea how to interact appropriately with their classmates. They simply lack the social skills needed to perform the most basic cooperative tasks. Lack of social skills is probably the biggest factor contributing to lack of academic success in teams. Fortunate social skills can be taught just like academic skills. Negotiation skills do not only refer to negotiating with others but with one's own self as well. For effectively negotiating with others, one needs to know what he wants in life, is firm as one's values and beliefs and can therefore say "no" to harmful behavior and risky situations. To avoid drug abuse negative peer pressure and other risky situations, adolescents need to develop negotiating skills. Non-judge mental skills are mainly needed by teachers or parents. For taking their own decisions, adolescents should be presented with pros and cons of a particular situation without elders imposing their own values on children. This will enable adolescents to take their own decisions independently. Teacher and parents should not be prescriptive as preaching may prove to be counterproductive. Empathy skill is the ability to imagine what life is like for another person, even in situation that we may not be familiar with. Empathy can help us understand how the other person feels in a particular situation and what his/her point of view is? Cultivating empathy for different groups in society can help reduce incidence of violence and abuse in the society. All the above mentioned skills are interlinked with one another (Seth, 2000). For example, the decision-making skill is likely to involve creative and critical thinking and value analysis. The base of good interpersonal relationship is empathy and habit of good listening. Having learnt to cope with emotions and stress also contributes to better interpersonal relationship with others.

To effectively influence the behavior, skill building in the target group needs to be content area or topic specific. We must be clear about what are we making decisions about. Learning about decision making will be more meaningful if the content is relevant and remain valid over a period of time. Developing skills related to various issues of physical and mental health of adolescents with special needs requires the proper development of above mentioned skills. Some of the personal social skills such as achieving self-awareness, acquiring selfconfidence, achieving socially responsible behavior, maintaining good interpersonal skills, achieving independence, making adequate decisions, communicating with others etc are to be developed among adolescents. Skills enable adolescents to translate knowledge, attitudes and values into actual abilities that enable adolescents to behave in healthy ways, given the desire to do and given the scope and opportunities to do so (WHO, 1997). In skill development, the emphasis is more on "What to do?", and "How to do". Before we can help students improve their social skills, they need to understand why these skills are important. Some students have problems in cooperative learning teams. A crucial ingredient in employment success is the development of adequate work habits and personal social skills. More specific to successful employment are the social-vocational skills of: 1) independently managing one's activities; 2) meeting minimal cleanliness and dress requirements; 3) getting along with colleagues and supervisors; 4) following directions, taking turns, sharing materials, patient waiting etc.; 5) punctuality; 6) time management; 7) active listening; 8) resolving conflicts; 9) keeping an orderly work environment; 10) following directions, paraphrasing; 11) staying with the team and sharing ideas maintaining a 
moral work ethic and friendliness on the job. The purpose of training of job-related social skills and other life skills is to teach adolescents these skills that will increase their opportunity for job success as well as social and personal adjustment in daily life. These can be taught either with a curricular or co-curricular approach following systematic instruction, repeated practice and feedback to the learner regarding the appropriateness of responses. Since social skills are generally learned through observing the actions of others, students are to be taught to refine their observation skills. They should also be taught to improve their interaction and problem-solving skills, to think before acting. Job related social skills can be developed through the training of different sections of activities like 1) instructional guide; 2) job skills training format; 3) self-management strategies; 4) job-related social skills evaluation; 5) monitoring students on the job; 6) appendices etc. The job-related social skills can be listed as: 1) ordering job responsibilities; 2) understanding instructions; 3) making introductions; 4) asking questions; 5) asking permission; 6) asking for help; 7) accepting help; 8) offering help; 9) requesting information; 10) taking messages; 11) having a conversation; 12) giving directions; 13) receiving compliments; 14) and giving compliments etc. Being a counselor or teacher we can prepare an Individualized Transition Plan taking into accounts all the above skills and organize the transition skill training programme for the adolescents with special needs. Such type of pilot projects have already been initiated by NCERT (2002), UNFPA, (i.e., National Population Education Project, 2002) to test the effectiveness of different strategies of skill training among adolescents and youths.

\section{Conclusions}

However, in order to make such (and many others) programmes more effective, efforts should be made to sustain them over a larger period of time as skill building occurs after repeated practice. Network of skill building activities should be extended to the community/out-of-school youth and children with differential needs, so that students would be able to find favorable environment both in the school and out-of-school in the community, which act for them as a laboratory of real life situation and also help the adolescents with special needs.

In USA Vocational Rehabilitation is a federal program whose purpose is to empower individuals with disabilities to achieve gainful employment consistent with their strengths, resources, priorities, concerns, abilities, and capabilities, so that they can prepare for and engage in gainful employment. The disabled people should be empowered to maximize their economic self-sufficiency, independence, and inclusion/integration into society through comprehensive vocational training programmes. In fact, these individuals should be active participants in their own rehabilitation program and can make meaningful and informed choices in selecting personal vocational goals and vocational Rehabilitation services.

Moreover, support for family involvement as well as systematic advocacy and community involvements are also being facilitated. The Vocational Rehabilitation agencies usually take the charge of these services, by following the guidelines of the governments. Another initiative taken by the US federal government is the STWO Act (School-to-Work Opportunities Act, 1994) which ensures a national framework for the development of School-to-work opportunities for every state and provides funding to enhance the opportunities for youth to gain technical skills and education that would assist them in transition from school to work. In fact STWO Act strives to build the partnership among the public school system and private business intended to increase the relevance of school-related activities to the requirements of the workplace.

In this context some authors have suggested for a new paradigm of integrating vocational psychology and counselling psychology. Thus, vocational issues are viewed as primary issues and contextual factors in people's lives. The vocational factors will provide another facet to understanding the multiple life roles and complex contexts in which we live (Robitschekz \& De-bell, 2002). This new paradigm conceptualizes vocational issues as an integral part of theory, research and practice, and counseling psychology. Hence, vocational issues should be an integrated part of counselling psychologists’ practices.

\section{References}

Chamberlain, M. (1998). Employers’ Ranking of Factors Judged Critical to Job Success for Individuals with Severe Disabilities. Career Development for Exceptional Individuals, 11, 141-147.

Clark, G. M. (1994). Is a Functional Curriculum Approach Compatible with an Inclusive Model? Teaching Exceptional children, 26, 36-39.

Clark, G. M., \& Kolstoe, O. P. (1990). Career Development and Transition Education for Adolescents with Disabilities. 
Boston: Allyn and Bacon.

Cobb, B., \& Brody-Hasazi, S. (1987). School-Aged Transition Services: Options for Adolescents with Mild Handicaps. Career Development for Exceptional Individuals, 10, 15-23. http://dx.doi.org/10.1177/088572888701000105

Edgar, E. (1987). Secondary Programs in Special Education: Are Many of Them Justifiable? Exceptional Children, 53, 555-561.

Edgar, E. (1988). Employment as an Outcome for Mildly Handicapped Students: Current Status and Future Direction. Focus on Exceptional Children, 21, 1-8.

Kranstover, L. L., Thurlow, M. L., \& Bruininks, R. H. (1989). Special Education Graduates versus Non-Graduates: A Longitudinal Study of Outcomes. Career Development for Exceptional Individuals, 12, 153-166.

http://dx.doi.org/10.1177/088572888901200211

Laus, M. (1977). Travel Instruction for the Handicapped. Springfield, II: Charles C. Thomas.

Michaels, C. A. (1989). Employment: The Final Frontier: Issues and Practices for Persons with Learning Disabilities. Rehabilitation Counselling Bulletin, 33, 67-73.

National Council of Educational Research and Training (2002). Skill Building through Adolescence Education: A Pilot Project Design. New Delhi.

National Population Education Project (2002). Ministry of Human Resource Development, Government of India.

National Sample Survey Organization (2002). Ministry of Statistics, Government of India.

National Transition Longitudinal Study (1994). National Transition Longitudinal Study: Post School Outcomes of Students with Disabilities (Contract Number: 300-87-0054). Washington DC: US Department of Education.

Patton, P. L. (1991). A Survey of Employers of Students with Mild Disabilities. Unpublished Manuscript, San Diego.

Robitschek, \& De-bell (2002). Traditional and Emerging Career Development Theory. In D. L. Blustein (ed.), The Oxford Handbook of the Psychology of Working. https://books.google.co.in/books?isbn=0199758794

School-to-Work Opportunities Act (1994). US Departments of Education and Labor. www.newwaystowork.org/qwbl/....Factsheets/schooltoworkact

Seth, M. (2000). Planning Life Skills Education for Adolescent: Incorporating Reproductive Health and Gender. New Delhi: UNFPA.

UNESCO (2001). Life Skills on Adolescent Reproductive Health. Bangkok: UNESCO.

Wehman, P. (1993). Life beyond the Classroom: Transition Services for Youth with Disabilities. Boston, MA: Paul H. Brookes.

WHO (1997). Life Skill Education in Schools. Geneva: WHO (Division of Mental Health and Prevention of Substance Abuse). 
Scientific Research Publishing (SCIRP) is one of the largest Open Access journal publishers. It is currently publishing more than 200 open access, online, peer-reviewed journals covering a wide range of academic disciplines. SCIRP serves the worldwide academic communities and contributes to the progress and application of science with its publication.

Other selected journals from SCIRP are listed as below. Submit your manuscript to us via either submit@scirp.org or Online Submission Portal.
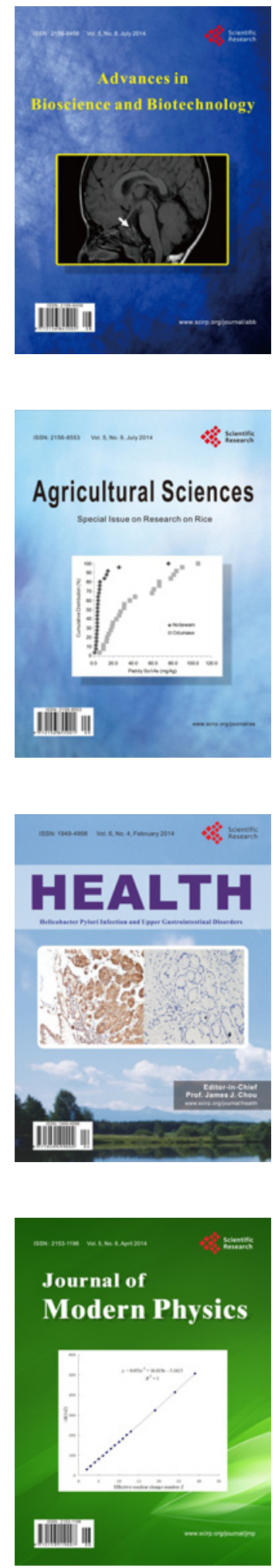
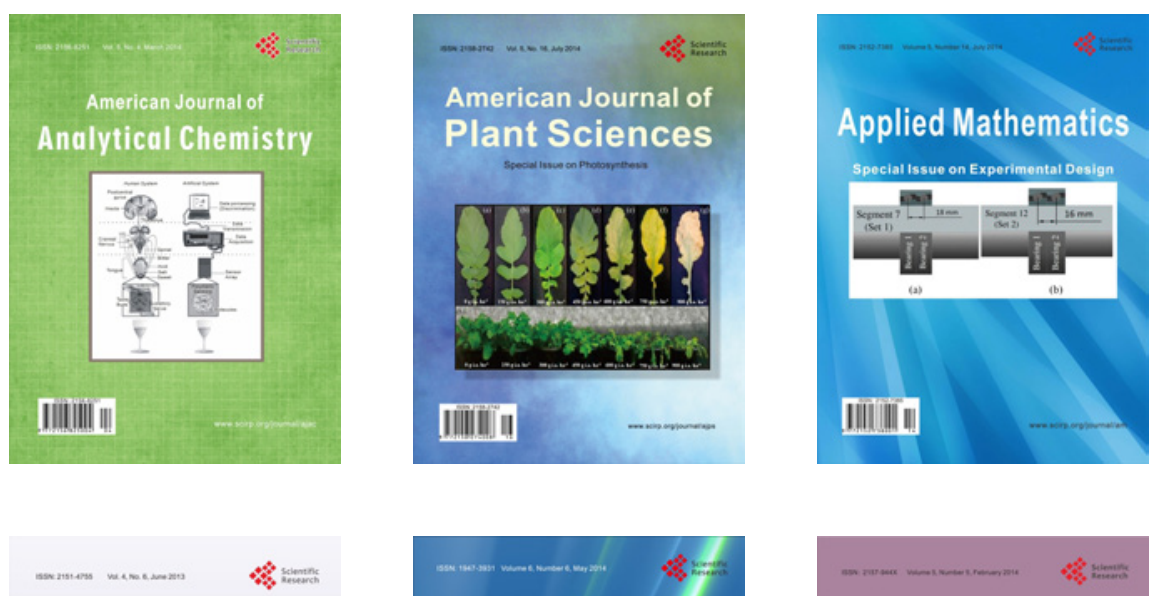

Creative Education
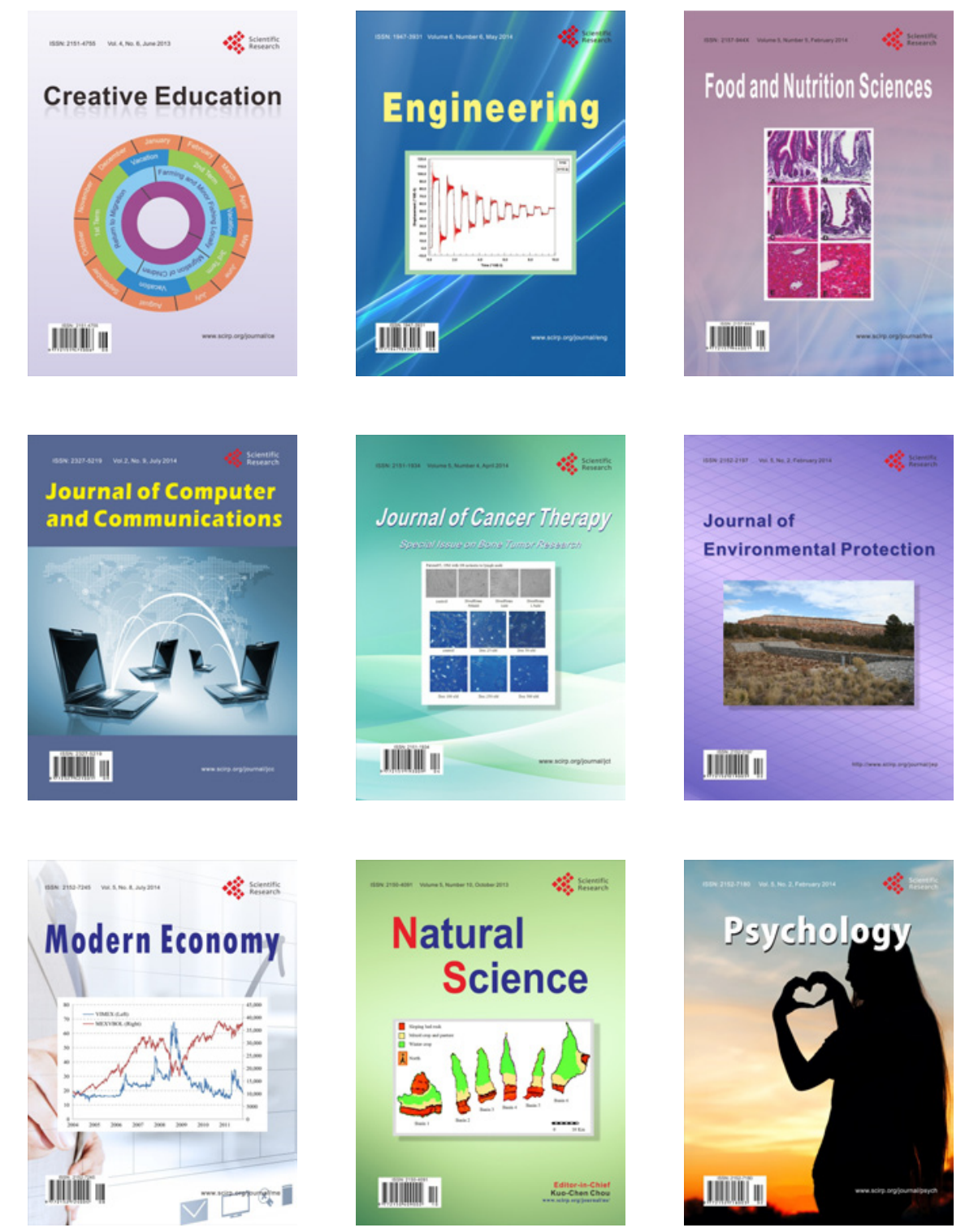